\title{
ANALYSIS AND SIMULATION FILTRATION ORE DURING THE PROCESS OF ORE ENRICHMENT
}

\author{
Paweł MAŚLAK ${ }^{1}$, Tomasz DOBOSZ ${ }^{2}$ \\ 1 University of Science and Technology, Faculty of Mechanical Engineering, Department of Machine Design \\ and Research, 5 Łukasiewicza st., 50-370 Wroclaw, Poland, e-mail: pawel.maslak@pwr.edu.pl \\ 2 University of Science and Technology, Faculty of Mechanical Engineering, Department of Machine Design \\ and Research, 5 Łukasiewicza st., 50-370 Wroclaw, Poland, e-mail: tomasz.dobosz@pwr.edu.pl
}

\section{Introduction}

Nowadays during the process of underground mining there is a lot of explosive materials used. After that a lot of waste from explosive materials get to the ore. Valuable ore materials are mined with its unavoidable mix of unwanted solids. After getting the ore from underground it needs to be prepared for the melting process. That process is called ore enrichment. After that the ore from 2$3 \%$ of valuable metal can reach about $30 \%$ of metal.

\section{Analysis of the ore}

During the transport of the ore the sampling and the analysis are being processed. Sampling is the removal from a given lot of material a portion that is representative of the whole yet of convenient size for analysis. After one or more samples are taken from an amount of ore passing through a material stream such as a conveyor belt, the samples are reduced to quantities suitable for further analysis. However sometimes it is impossible to take the best number of samples.

At the beginning a morphological analysis of the ore should be carried out. The view from the morphological analysis are shown in the figure 1. The morphological analysis shows that there is a lot of gravels.

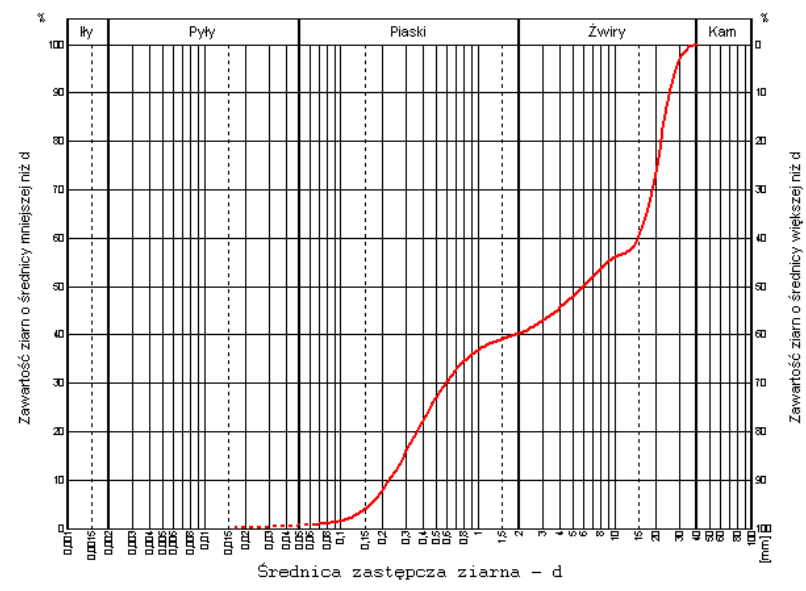

Fig. 1. Morphological analysis of the ore.

The next step while improving the enrichment process is to check what type of contaminants are found in the spoil. During the research it was found that the materials waste can be grouped into 6 groups:

- Wooden wastes

- Explosive wires

- Metals

- Rubbers and plastics

- Textiles

- Foils

The materials are found at the different place during the process of enrichment. All of them need to be separated as soon as possible to avoid them in the further steps of enrichment process. In the figure 2 there are shown the found unwanted materials in the ore. 


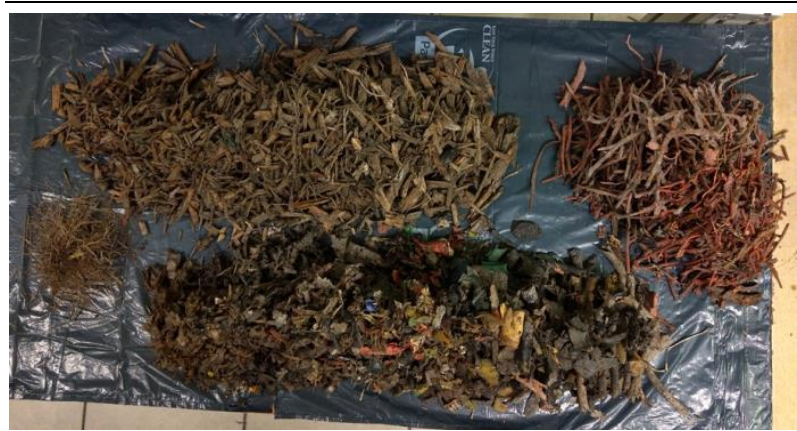

Fig. 2. Unwanted materials found in the ore.

Table 1. Unwanted materials in one sample.

\begin{tabular}{|c|c|c|}
\hline Case no. & Group of material & $\begin{array}{c}\text { Mass } \\
{[\mathbf{g}]}\end{array}$ \\
\hline 1 & Wooden waste & 965 \\
\hline 2 & Explosive wires & 700 \\
\hline 3 & Metals & 33 \\
\hline 4 & Rubbers and plastics & 915 \\
\hline 5 & Textiles & 565 \\
\hline 6 & Foils & 105 \\
\hline
\end{tabular}

After the morphological analysis of the waste found in the ore the biggest amount are wooden waste and the rubber and plastics. Wooden waste are the most problematic during the next enrichment processes.

\section{Filtration simulation}

The filtration is designed to detect as much as possible impurities in the ore. Nowadays the filtration process is unsatisfactory. That process need to be autonomous, self-cleaning and not affecting the enrichment process, so the research were carried out. Present filtering process is shown in the figure 3 .

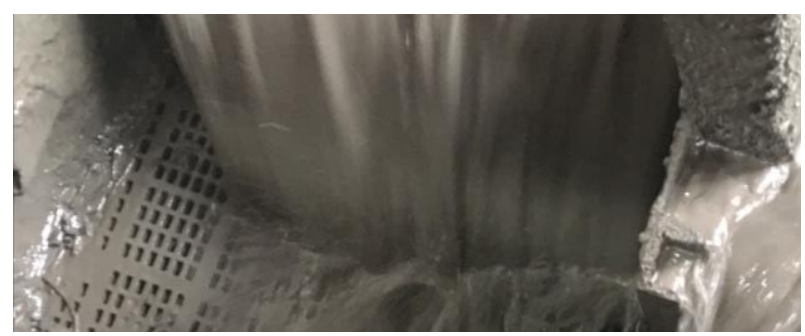

Fig. 3. Filtration process.

\section{Filtration simulation}

The Filtration simulation was prepared to achieve the best size of holes in filtration shells.

Analysis with different type of falling elements were carried out - different size and different mechanical properties were simulated. In the full article there are shown the results from much more simulations. The view from the simulation is shown in figure 4.

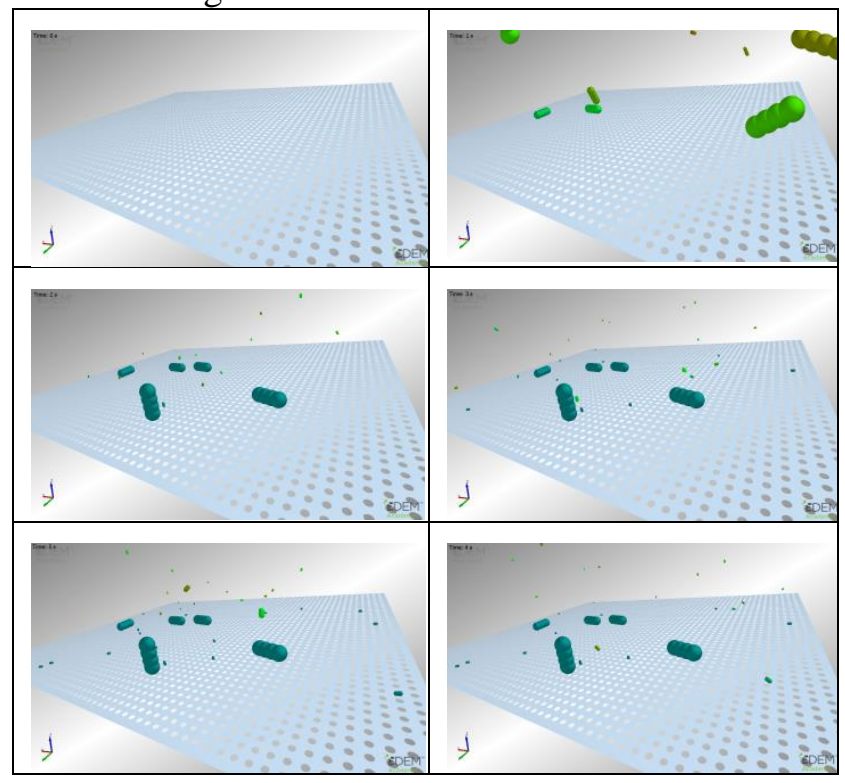

Fig. 4. View from the filtration simulation.

\section{Conclusions}

Analyzing the entire ore enrichment process is very necessary, as it allows the determination of process points that are key to improving the efficiency of the entire process. numerical modeling of the filtration process allows to accelerate the implementation phase of the filtering system change. The filtration simulation shows what kind of filter will be the best solution for the ore enrichment process.

\section{References}

[1] Rusiński E., Czmochowski J., Smolnicki T.: Zaawansowana metoda elementów skończonych $w$ konstrukcjach nośnych, Oficyna Wydaw. PWroc., 2000

[2] Maślak P., Smolnicki T. Strength and Fatigue Analysis of the Welding Connection on the Compressed Air Tank, Proceedings of the 14th International Scientific Conference: Computer Aided Engineering, Springer 2018

[3] Mike D. Adams, Gold Ore Processing: Project Development and Operations, Elsevier, 2016

[4] SHARMA B.K., Industrial Chemistry Krishna Prakashan Media, 1991 